GABRIELLA SPINELLI

Brunel University

\title{
Innovation is in the eyes of the beholder: the case of the ageing consumers
}

\begin{abstract}
This research considers innovation from the user point of view in order to enhance the design and commercialisation of technology-based products. Previous studies predominantly analyze innovation as a function of technology advantage; that is how new competitors who have advanced R\&D can challenge the incumbents' position. However little is understood about the potentially ambiguous position that technology-based products may have on the market due to the diverse perception that different market segments may hold of such products. Consequently innovations studies are limited in overlooking innovation as function of users'/consumers' perception. The findings of this research reveal that innovation may be disruptive and evolutionary at the same time for different consumers groups. Consumers' perception of technology products can influence their decision-making prepurchase as well as their level of adoption. Analogical learning, or the inability to apply it, is in part responsible for the choices that consumers make when considering whether to purchase, use and discard technological products. Exposure and familiarity with the product category are also factors that influence consumers' perception, especially among the ageing segment of the population. The ambiguity of products' perception represents an unusual puzzle for businesses that are now required to alter design features and marketing communication strategies to appeal to different consumers despite the product is inherently the same from a business point of view.
\end{abstract}

\section{Keywords}

Innovation, Innovation Overload, Product Design, Ageing Consumers, Inferential Analogy

\section{Introduction}

The literature refers to the introduction and application of technological advancement in product development and manufacturing as the origin of innovation (Baglieri 2003). The managerial process that underpins product development and production, such as lean management, has also been identified as a source of innovation (Womak, Jones and Ross 1991). In these approaches the agency of innovation is firmly placed with the firms. Recently Verganti (2002) has suggested that innovation may also originate from unfulfilled user needs and requirements and he designates such phenomenon as a design-driven innovation.

In parallel with a growing complexity in technology and new production methods, we are also experiencing an ever-growing complexity in the sociocultural context we inhabit and also contribute to form. Phenomena such as globalization, resource finiteness and unprecedented longevity are new challenges to our sense making, meant as our ability to organize and act in 
the unknown (Weick 1993; 1995). While the meteoric progress of technology enhances the opportunities for innovation, meant as a paradigm shift or permutation, it also creates room for ambiguity. In this resulting complex environment researchers have already acknowledged that the symbolic meaning of every day actions and products is no longer attributed to or recognized in univocal and unequivocal way (Burdek 2005) and that interpretative flexibility is used to analyze and relate to new technology (Bakardjieva and Smith, 2001).

By 2035 twenty-three percent of the population in the UK will be 65 and over (Office of National Statistics, 2009) and similar trends are observable in other European countries (Eurostat, 2010). Japan, the US, New Zeland and Canada offer comparable data (Population Reference Bureau, 2010). Historically this is the first time that older segments of the population have reached such a presence in society with a consequent stronger consumer voice. The diversity among ageing groups is striking and leads to different perceptions of the many products that surround us. This holds true especially in the domain of technology-based products, a fast growing sector that, given the speed of R\&D and associated reduction in cost, has dramatically changed many aspects of our everyday life.

Given the current socio-cultural complexity and in line with literature on social-construction of technology (Griffith 1999) this paper argues that innovation cannot be understood just as a function of corporate- and technological- driven forces. It should be also analyzed as the outcome of the consumers sense-making within the framework of their experience and the socio-cultural context they belong to. In other words, this research looks at the ageing consumers as the sense-making agent who perceives, adopt or reject technological products by operating a categorization of what represents innovation and of what form, e.g. radical, evolutionary, disruptive. This multitude of individual products' sense-making compels designers and marketers to reconsider if, how and for whom they conceptualize and commercialize innovation.

\section{Understanding innovation}

More than two decades ago Christensen (1997) stressed the dilemma that firms have to face when trying to stay relevant and to grow in the market. The author captured the dilemma by saying that "sound execution, speed-tomarket, total quality management and process reengineering are equally ineffective" (idem:xviii) when firms faced disruptive technologies. In Christiansen's account the disruptive type of innovation changed the 'rules of the game' and indeed focused the future innovation debate on how to understand market strategies as function of the type of innovation to be launched on the market. Scholars have dwelled extensively on how to categorize innovation, predominantly considering its causes of origin as determinants of the specific category. To this effect Pavitt (1984) arranged innovation according to the firms that generates it with the purpose of describing the behavior of innovating firms and consequently identify successful market strategies. Durand (1992) suggested a categorization based on intensity and significance of innovation and in his taxonomy 
Perception of the Market is one of the four dimensions considered. Other categorization techniques rely on the change or impact that the technological innovation delivers. A very well known example of this approach is the tripartite taxonomy of Freeman and Soete (1987) where innovation is classified as incremental, radical or as a technological revolution. In these traditional models of innovation, the role of consumers is to have needs that firms and manufacturers fulfill. In this view, the agency of innovation is firmly placed among those who sell innovation to the market.

A new approach to the study of innovation has come from scholars interested in user-led Innovation. It is claimed that increasing access to technologies, easiness of use, social networks and virtual communities have facilitated the role of the end-users as agents of innovation. User-led innovation is currently seen as a powerful phenomenon where users develop their own product with several advantages such as precise customization and reduced degree of risk because they are in charge of the development of the novel products. Studies also recognize that those users who make product changes have the profile of lead users (Olson and Bakke 2001; Lilien et al. 2002, Morrison et al. 2004) meaning that they are able to interpret market trends and carefully develop solutions highly effective for the requirements they have. von Hippel (2005) also argues that it is reasonable to think that the product development performed by lead users is highly relevant and desirable from a commercial point of view. These increased design capabilities in the hand of end-users, while making innovation a more democratized process, are also challenging current business models that have traditionally underpinned the creation and commercialization of innovation by firms. However, access and familiarization with technologies that equip users with the skills to initiate product development as part of a more democratic process of innovation are not features equally shared among the population segments. The ageing consumers, who traditionally have enjoyed less exposure, hence less experience with digital tools, can hardly be defined as innovators in the technology market and need to rely on off-the-shelves products to suit their needs.

There are many theoretical models that have attempted to explain technology acceptance and diffusion of innovation. These extant theoretical contributions have been criticized for their partial validity and for focusing on relatively simple technology (Venketash et al 2003). While they all contribute differently to the field of technology acceptance, one emerges as particularly relevant to innovation due to its applicability to, and indeed inception from, domains unrelated to technology. The Innovation Diffusion Theory (IDT) has been applied since the 1960 to understand and to size up market opportunities (Rogers 1995; Rogers and Shoemaker 1971). In IDT five key factors were identified as relevant in affecting innovation diffusion, these were Relative Advantage, Compatibility, Complexity, Triability and Observability (Rogers 1995). Later on in the domain of Information Systems, scholars further articulated the initial five factors and added Ease of Use, Image and Voluntariness of Use as additional determining factors in diffusion (Moore and Benbesat 1991). 
Ageing individuals do not fit the profile of early adopters (Rogers 1995) or lead users (von Hippel 1988; 2005) and are commonly depicted as late adopters and laggards (Herbig and Kramer 1992). However considering their increasing number in Western and Eastern societies, it is relevant to ponder how technology-based products score in terms of characteristics of innovation against the needs, requirements and aspirations of older people. Studies in gerontology and psychology offer us tremendous insights in how the ageing mind works and how it changes. Cognitive ageing is no longer considered a matter of simple decline but a complex process of advancing limitations and cognitive pragmatics (Baltes and Plank 1993). The latter are culturallyacquired experience-based heuristics that compensate for the loss in abilities that occurs with age, yet enhancing decision-making. The application of cognitive pragmatics has been largely studied in consumer behavior and choice (Drolet et al 2010; Yoon et al 2009).

Innovation Overload (Herbig and Kramer 1994) may be a threat to ageing consumers in the decision-making process that leads to the adoption, or rejection of new technology-based products. The lack of familiarity and relative less developed computer literacy among the elderly segments of the population can make them more prone to such risk. Innovation overload consists in the inability to focus on and select the relevant and desirable innovation characteristics as criteria for choice (Herbig and Kramer 1992). Innovation Overload has been applied to understand the factors that hinder adoption rather than those that afford the same, as Venkatesh et al (2003) discussed. Hirschman's approach to innovation diffusion (1987) represents the first step in the formalisation of the concept of Innovation Overload. Interested not merely in technical innovation but also in innovation loaded with symbolic value, Hirschman argued that innovation is always in flux even while the consumer decision-making is taking place, making the landscape of choices more complex. Differently interested in innovation, Hirschman's work takes a qualitative approach and starts from the review of service innovation. From the case of childcare service, Hirschman crystallized five propositions. These propositions help us understand how Innovation Overload can take place and manifests itself when consumers face an upward trajectory of complexity which is surrounded by uncertainty (ibid:57) When faced by choice in an unknown realm, users/consumers consider and enact all or some of the following strategies:

1. Postpone decision-making; this is not always a strategy adopted out of disinterest or lack of care, but a position taken when the consumer may need to have a first-hand experience of a role/set of circumstances never encountered before. The inability to compare the new situation to the past may freeze the decision making until the consumer feels she/he has had the basic competence to adopt innovation;

2. Discard symbolic aspects of the choice as no prior experience is available; this behavior consists in the preference to make choice of adoption based on tangible aspects of the innovation, rather than its symbolic characteristics as the consumers in unable to understand or value the latter;

3. View functional expectations of the innovation based on past experience; potential innovations are likely to be compared to past consumer 
experience and in this process the consumer develops the mental model necessary to evaluate new alternative choices. In such process of comparison and evaluation, past experience makes us focus on functional aspects of the new solutions as these are easier to translate from past to future choices.

4. Be influenced by social class (and peer pressure); how we fit in society and how other see us, may condition our behavior, henceforth consumers will make choices that are generally consonant with the community, class and cultural context they feel they belong to.

5. Accept a lower performance threshold when complexity proliferates in the innovation domain; innovative choice and potential new products do not hold still while we make a decision. Instead the landscape is in continuous evolution and the fast products' lifecycle can make consumer choices obsolete while they are still in the making. In this respect, consumers may precipitate their choice and accept a less than optimal performance from their new product because they can no longer cope with the uncertainty and risk they are dealing with.

When encountering technology-based new products older consumers are faced by a compound complexity: on the one hand the nature of the innovation is fast paced, ever changing and difficult to map; on the other hand, their lack of extensive experience with this product category impedes an effective transposition of knowledge developed from past experience to operate choices in a new domain. Studies in psychology have looked at the inferential strategies people adopt when they encounter new products. Marketers have also taken a keen interest in this topic because the ability to distinguish between incrementally new products (INPs) from really new products (RNPs) is crucial in consumer behavior (Gregan-Paxton and John 1997). Theories of learning have been frequently referenced in marketing to explain how consumers understand what a product is. Lehmann (1997) asserts that RNPs cannot be understood by applying category-based learning as RNPs -by definition- create new categories. Analogical learning has been discussed as a more effective way by which we learn knowledge about RNPs. When bridging the conceptual distance between known products and RNPs consumers transpose the links between features and benefits they have created for known products to RNPs (Gregan-Paxton and Roedder John 1997). This mapping is also known as relational analogy. A central element in learning by analogy is the concept that knowledge is transferable from an existing knowledge structure, the Primary Base Domain (PBD) to a totally new situation or product, the Target. Adoption then takes place when the consumer achieves a high comprehension of the new product and when the consumer is able to perceive the relative advantage of the RNP (Moreau et al 2001).

In the process of relational analogy known products are used as templates to create a structural correspondence with the new products (Klein 1987). Learning by analogy comprises of three stages: access, mapping and comprehension (Gentner 1989; Gregan-Paxton and Roedder John 1997). Initially the consumer must activate and access a relevant PBD. This activation can be facilitated by spontaneous or prompted stimuli if the known 
product and the RNP share visible characteristics. Once the primary based domain is activated, the consumer maps similar elements in the base and target domains. The mapping process becomes easier if the structural correspondence between the base and the target domains is high. At this stage both attributes and relations can be mapped. The former are components of the product while the latter are associations between the components and the functionality of the products. Users prefer relation-based mapping because they support the development of a goal-based map of the new product (i.e. how it works and what it can do), but goal-based maps are more accessible to expert users than novice ones. In the stage of comprehension the transfer of knowledge takes place between domains. In incremental innovation, novice users have a less developed PBD, hence their cost of learning about the target domain is higher. However some studies have discovered quite counter-intuitively that expert users may find more difficult to comprehend discontinuous innovations. This is caused by their advanced PBD that hinder their ability to understand the target domain due to the high cognitive cost in adjusting the many attributes and relations that do not map into the target domain. Similarly for the understanding of relative advantage and risks of RNPs, experts will be better equipped to understand relative advantage and risks for incremental innovations, but will be left with many unresolved knowledge gaps when faced by discontinuous innovation, hampering their overall comprehension.

It has been also claimed that a PBD may not be enough to develop a mental model of a RNP. In such circumstances supplementary knowledge base (SKB) may be needed. This is the case for example of technology-based products that bring together functionalities that traditionally were performed by different artifacts, e.g. a digital camera. However the additional comprehension that a supplementary knowledge base allows will be effective only if there is an expert entrenched knowledge of the PBD (Gentner 1983). The consequences of learning by analogy for consumer behavior are both quantitative and qualitative; when a consumer faces a target domain that contains both mapped and unmapped elements to the PBD, fewer mapped elements will be remembered and elements not mapped back to the PBD will be discarded in favor of mapped elements (Gregan-Paxton et al 2002).

So far analogical inference has been the most powerful mechanism identified by scholars in the investigation of how people acquire new knowledge structures. Understanding this cognitive mechanism impacts how innovation is designed and communicated. As the tremendous pace of technology innovation brings more and more products to the market where consumers are differently equipped to understand and adopt new products, it is imperative to realize that innovation can be ambiguously perceived, flexibly interpreted and diversely adopted. However it is for the first time that society is experiencing such strong and diverse demographic segments who have equal interest in making sense and use of the fast changing landscapes of technological products and will do so as a function of their own personal entrenched knowledge structures. The central tenet of this research is the investigation of how novices namely ageing consumers, make sense, learn, adopt and discard technology-based products. 


\section{The study}

This research sought to investigate how technology-based products are understood by ageing users. The study did not purposely distinguish between INPs and RNPs to start with as the research focus was in the understanding of the socio-cultural and cognitive elements that came to play a role in this distinction and, consequently, in the adoption patterns among the elderly.

Mainly drawn to develop insights in how ageing consumers perceive technology-based products, the study adopted a contextual inquiry and interpretative approach (Wixon et al 1990). This allowed for the consideration of each study participant's storytelling as a case with social and cognitive characteristics, rather than dissecting the empirical data in support to a still underdeveloped understanding of the complex relation between ageing and technology adoption.

The data collection took place by the means of semi-structured interviews led by the same researcher throughout so as to enhance the consistency of the interaction with the participants and control potential bias. The interviews were all audio-recorded and transcribed. 40 participants aged 60 years old and over took part in the study. In line with the contextual inquiry method and other interpretative studies with ageing participants (Price et al 2000), all interviews took place at the participant's residence. The participants were equally split by gender and country of residence; London in the UK and Tokyo in Japan. By including participants from two countries the study aimed to capture how the diversity of the two socio-cultural contexts might have influenced adoption choice. The choice to focus on two metropolitan areas was dictated by convenience and by the desire to limit wide variations that we predicted to occur would we have included participants from rural UK and Japan.

Beside the age and geographical requirements built in the sample selection, see table 1 for full details, we asked of participants to have at least a basic level of familiarity with technology. We articulated such requirements by providing potential candidates with a list of tasks we expected them to be familiar with. This list included: browsing the internet, sending and receiving text messages with a mobile phone, consistent use of email, using digital cameras, shopping online, the usage of word processing software.

$\begin{array}{cccccccc}\text { Name ID } & \text { Location } & \text { Gender } & \text { Age } & \text { Name ID } & \text { Location } & \text { Gender } & \text { Age } \\ \text { Molly } & \text { London } & \text { F } & 70 & \text { Hiromi } & \text { Tokyo } & \text { F } & 61 \\ \text { Maria G } & \text { London } & \text { F } & 60 & \text { Sachie } & \text { Tokyo } & \text { F } & 63 \\ \text { Chitra } & \text { London } & \text { F } & 70 & \text { Harumi } & \text { Tokyo } & \text { M } & 74 \\ \text { Gillian } & \text { London } & \text { F } & 62 & \text { Terumi } & \text { Tokyo } & \text { F } & 71 \\ \text { Gerard } & \text { London } & \text { M } & 84 & \text { Hiroshi } & \text { Tokyo } & \text { M } & 68 \\ \text { Raymond } & \text { London } & \text { M } & 69 & \text { Setsuko } & \text { Tokyo } & \text { F } & 68 \\ \text { Wendy } & \text { London } & \text { F } & 66 & \text { Tatsuo } & \text { Tokyo } & \text { M } & 63 \\ \text { Maria } & \text { London } & \text { F } & 78 & \text { Yukiko } & \text { Tokyo } & \text { F } & 60 \\ \text { Malcolm } & \text { London } & \text { M } & 68 & \text { Kenichi } & \text { Tokyo } & \text { M } & 76 \\ \text { Rose } & \text { London } & \text { F } & 64 & \text { Masumi } & \text { Tokyo } & \text { M } & 64 \\ \text { Mary F } & \text { London } & \text { F } & 65 & \text { Ituko } & \text { Tokyo } & \text { F } & 61 \\ \text { Precious } & \text { London } & \text { F } & 66 & \text { Kujiko } & \text { Tokyo } & \text { F } & 67 \\ \text { Alan } & \text { London } & \text { M } & 70 & \text { Mikihiko } & \text { Tokyo } & \text { M } & 67 \\ \text { Annette } & \text { London } & \text { F } & 70 & \text { Toshiki } & \text { Tokyo } & \text { F } & 68\end{array}$




$\begin{array}{cccccccc}\text { Chris } & \text { London } & \text { M } & 69 & \text { Hideyoshi } & \text { Tokyo } & \text { M } & 67 \\ \text { Richard } & \text { London } & \text { M } & 75 & \text { Junichi } & \text { Tokyo } & \text { M } & 69 \\ \text { Dennis } & \text { London } & \text { M } & 78 & \text { Minoru } & \text { Tokyo } & \text { M } & 66 \\ \text { Alfred } & \text { London } & \text { M } & 83 & \text { Ryuzou } & \text { Tokyo } & \text { M } & 82 \\ \text { Kieron } & \text { London } & \text { M } & 63 & \text { Kumiko } & \text { Tokyo } & \text { F } & 72 \\ \text { Bernard } & \text { London } & \text { M } & 74 & \text { Kyoko } & \text { Tokyo } & \text { F } & 63\end{array}$

By occurring at their place of residence, an environment extremely familiar to the participants, the interviews capitalized on the presence of technologybased products as probes for the interview. A fall back position consisted in a list of questions the interviewer had prepared prior to the visits about technological devices, their purchase, their usage, their benefits and the challenges they created. During the interviews story telling developed with ease in the majority of cases and the researcher was allowed to observe and photograph devices and contexts of use. Interviews lasted between 53 and 125 minutes.

The findings section below is organized in three sections to reflect the significance of the identified themes: innovation overload, learning by analogy and coping strategies.

\section{Findings}

As we wished to understand the relation between ageing people and innovation adoption, the participants' usage of technology, regardless of the level of usage, demonstrated interest in the product category. When making general considerations about the sample it is fair to say that the average understanding of technologies was basic to fair, that those who were still in paid work had a more advanced knowledge of technologies and that technology-based products had manly been adopted to communicate with family and friends.

\section{Innovation Overload}

The adoption of technology was in most cases driven by necessity. Yukiko is an example of this; her mother lives in Sapporo and she is 90 years old. In order to enhance their communication, e.g. share photos, they bought the same mobile phones. Yukiko taught herself how to use the phone basic functions and then explained to her mother how to use the mobile phone over the landline phone. Buying the same device is also a popular strategy to minimize learning that we encountered with other participants.

The purchase, usage and sometimes the mere existence of new technology products caused anxiety, frustration and fear among the participants. This seemed to influence the number and type of technology they would consider useful. To exemplify this point here is an extract from the interview with Fumiko: "Companies develop lots of new products and l'm not interested. It's good for Japan to develop products to sell to the world but, for me, as an elder, in the daily common life I actually think -please stop developing new things-". The innovation overload created by technology also seemed to threaten individual emotionally and not only challenge them cognitively. Kujico 
says: "I wish to go back to 300 years ego, Edo era, where there were no computers and then I could be top of the class. I feel very undermined by the difficulties in learning to use a PC. Technologies are enemy".

Participants also expressed a fear that technology would take over if it took too much time or attention in their life. This potential threat was elicited by Gillian:"[...] but I don't want to be stuck to it, I don't want to be totally immersed in it, I don't want to lose contact with the real world -you know". Richard also mentioned: "We don't want to be ruled by the computer, we are quite happy to control our use of the computer. If I need it at night we have it on at night, but in terms of control I have no wish to be controlled by technology". There are two aspects in which this threat to be controlled is perceived; one is a threat to free will, disposing of one's time and actions, and the other threat is to privacy when technology can provide too many opportunities for unsolicited and untimely communication. Rose at this regard says: "Partly because I like boundaries and I don't like...I don't want to communicate with everybody all the time, I do.... I just feel that you kind of lose control of your personal information, I don't know it's just my personal feeling". Kujiko very poignantly states that: "My mobile phone is a sweet gift from the enemy, which I do not trust in full. If there was no phone nowadays, I could write beautiful letters to my son, but the enemy has brought in these technologies that I must use because of the real time response (AN: it allows). A mobile phone (AN: communication) is like a cup noodles, a smart enemy. Technology cannot make me happy". The metaphor used by Kumiko who sees technologies as a fast food where the experience is compromised is also reflected in Chris's views of how technology are creating a layer that stop us from having real experiences. He says: "Young people are not paying attention to their surrounding they are losing a whole amount of enjoyment and interest. They don't listen to birdsong, they trip on flowers, they don't look at other people". Finally Mikihiko expresses the complexity that technological innovation is creating for society at large by saying: "The world would be more peaceful without computers. For example the stock market would be better without computers, more stable".

Technology-based products have been adopted and learned by necessity generated by personal and professional circumstances. So technology innovation is in most cases associated with work practice, laborious hours of training to comprehend them and very rarely with fun. An excerpt from Annette's interview states this clearly: "I regard it (AN: PC) as a sort of work so I prefer it to be out of the way, I wouldn't like to see it by the corner chair". Another participant, Terumi, in her house attempts to make technology-based products more enjoyable by embellishing them with crafted objects she makes herself "because they (AN: technologies) are no fun".

The observed responses to Innovation Overload were diverse. Some express frustration, for example Fumiko says: "I hate when I need to learn a new product. It (AN: learning) is too complicated, for the elderly, it's too difficult". Besides feeling inadequate and ill equipped to learn the use of new products, cognitive strategies were devised to cope in the given circumstances. These in the majority of cases had the aim to minimize the 
cost of learning. Ituko for example is accustomed to the software installed on her PC that allows her to print photos. She does not wish to change it and move to a software application that would allow her to download photos from her phone and print them all at the same time. She comments: "I am not interested in learning another software. I sometimes end up thinking that what I had before was better". Keeping complexity at bay with the intent to avoid overload made users to state the following:

- Haruni: "I only use what I need, I forget the rest exists";

- Hideyoshi: "I like this phone because it is simple. It has less functions"

- Hiroshi: "When I learn new technologies, I do not get angry or upset because I give up first!".

As an extreme measure to reduce functionalities overload with a new TV set (integrating cable and wireless Internet), Tatsuo marks with paper the buttons he had to use to switch the TV set on and off and to change channels (terrestrial ones). By physically obscuring the other buttons he prevented mistakes he felt he could not recover from.

\section{Learning by analogy}

An analogy is a heuristic employed to maximise past experience and accelerate the learning process. One of the side effects of analogical learning is that users would choose, when they are allowed, to purchase and adopt products that in attributes and functions resemble what they are already familiar with. The case of Hiromi provides a tremendous example of learning by analogy. Hiromi is 61 , married and mother of two. She lives in a wellappointed detached house in a residential part of Tokyo. She left full time employment when she started her family but she entered a PT teaching job when her two daughters left the house to get married. Unexpectedly Hiromi owned an old fashion washing machine. The appliance comprises of two circular tanks dedicated to washing and rinsing respectively. The washing machine needs the human intervention to load the laundry from the top when washing or rinsing. It also required the manual addition of water and soap to work. In brief the machine performs in an automatic way just the spinning that allows the clothes to be washed or rinsed. Hiromi mentioned that she has had this type of machine since it came out on the market and that she dreaded when they would be no longer viable as she disliked standard washing machines. Hiromi preference can be explained by considering two attributes of the appliance she owns:

1. there is minimal change between how clothes are washed by hand and how this task is performed by the appliance. The task (laundering) is isomorphic despite some part of it being automated;

2. the appliance can be stopped at any time (by just opening the lid of the tanks) to control and intervene, if necessary.

When choosing this type of appliance for the first time Hiromi had a map of the attributes and relations of the task "laundering" and this appliance offered the closest match possible. This allowed her to transfer her knowledge of 'how to do the laundering' to the appliance almost in full, with the exception of the use of the mechanical spinning that spared her the hard work. She disclosed a sense of anxiety if she had to make do with a machine she could not control. 
Kujiko also demonstrated how learning by analogy could break down when the analogy cannot be extended and the mapping between PBD and target domain is unfeasible. Kuiko is a retired woman who lives with her spouse, an engineer. She has been interested in technology for sometimes, especially in being able to use a laptop she received as a gift and a smart phone to stay in touch with her son who lives in Korea. She was motivated to learn the foundations of how a PC works as she thought that this knowledge would equip her with the ability to self teach more advanced skills at later stage. She grew impatient with the way she picked up few things about how to use her PC from her husband as she stated: "I was not much aware of all the functions of the PC, so I could not come up with what I wanted to learn". She decided to attend a course to gain a structured knowledge of computers and computing but the result was that she gave up the use of her PC. In her words: "I became afraid of computers. After understanding its complexity at the course and how far it was from what I thought it was I started feeling weary of breaking it".

Similarly Alfred explained his inability to "understand how it works" as he compared a laptop with a car that "I can open and replace a component that is not working, like a carburettor. Instead in it (AN: the PC) there is so much technology in there that something else will go wrong and that just irritates me".

Chris also discussed the inability to map the working of his smart phone onto something he had familiarity with and the resulting decision to waive the use of most of the phone functionalities. He said: "it seemed that if you made one mistake you are on a slippery slope, entering into abyss and you won't be able to get back". The smart phone proved to be too complex as a phone but easy to use as a simple digital camera. Chris went on to say: "we now have a second phone from my other daughter (AN: a traditional phone she cast off) and we use the smart phone to take photographs but not as a phone".

\section{Coping strategies}

So far we have reviewed how technology-based products can overload ageing users and how analogical inference helps but also hinders the learning in later life due to the lack or inadequacy of the knowledge in the PBD. Under this last theme, coping strategies, we aim to group and illustrate the observed and reported actions that ageing users put in place to cope. By coping strategies here we mean activities that span over the selection of technologybased products as well as their usage, as purchasing decisions are an important part in the determination of whether the same products will be used after purchase.

Harumi synthesises successfully why he needs to employ some coping actions in the face of an ever changing landscape of products: "With the technology always changing, it is necessary to face some risks if you want to advance your use of them". Despite Harumi perceived that 'risk' was a downside of technology-based products' adoption, he made a wide use of technology including online banking, MP3 player, game console, a digital 
radio. In his account the advantages of using such technology override his lack of familiarity with them as well as the potential breach of personal and financial data. Kujiko adopted a very different strategy when coping with technology-based products. As she was very frightened that the PC would break if she did something incorrectly, she decided to delegate the tasks to her husband, She says: "I am a dictator, I tell him what I want to do and he does it for me. I am very cautious [AN: with computers] and I am scared about the consequences of my actions". In her approach, Kujiko showed her appreciation for the meaningfulness and benefits of using a computer but the fit between her individual characteristics and the requirement of the tasks was low, hence she considered more relevant to delegate the tasks rather than to find ways to approach the technology. Similarly Alfred was delegated to perform tasks with technology to help his wife in emergency situations, while the couple's grandson who "was brought up on it (AN: technology) since the day he was born" is much more "knowledgeable and patient". Delegating partners and off-springs was a very common practice, especially for tasks that required a considerable level of resource investment but had to be performed only once, e.g. connecting printers, setting up emails' preferences, back ups, transferring contact detail.

Another observed coping strategy was training. Annette, reluctant to learn to use technologies by trial and error, said that: "I was not ready to use computer until and unless I had an idea on how to go about it. Basically if I want to know something I try to find a course and go on it'. Maria G.'s experience was similar: "I did not know even how to use a mouse. So I started to attend several courses and I felt like a complete idiot not only because I was not getting what it was taught but because people around me was getting it. They were much younger; I did not know the difference in uptake of technology with age. Their attitude and level were much higher. Took several courses that made me feel awful. Then by chance I found a course for elderly people. I was then 55 and the course was taught very slowly and I could relax and I did not feel like a fool".

To overcome anxiety another coping strategy was that of using aids. A power blackout during the earthquake in Tokyo erased all the settings on Sachie's PC and because her son, to whom set up tasks are delegated, lived far away, Sachie was unable to use her PC for long time. She therefore decided to keep a paper back-up of all preferences set up and contact details of the PC (printed screenshots). Chitra, overcome by the complexity of using three remote controls - to manage terrestrial TV, cable channels and VGR-, decided to devise a guide that in a nutshell would help her and her husband to remember the buttons and the sequences of commands associated to the functionalities of interest to them.

We observed that coping strategies were employed also to select products prior to purchase. Branded products and established retailers were consistently preferred. When we asked why branded products were considered better, the participants specified that it branded products and established retailers were selected they felt safer post sale in case the products were faulty. This selectivity in products and points of sale is another 
example of coping strategies put in place to reduce anxiety for a category of products the ageing consumers still lack confidence in.

A final and significant excerpt from Mary F's interview summarises, at least anecdotically, the general attitude of ageing users dealing with technologybased products. Mary F said: "[if a device stops working] the older people would likely think -oh what I have done now-. We take responsibility for something going wrong. Whereas the younger people automatically assume it is the system going down".

\section{Discussion}

Despite having some interest in the use of technology, the findings reveal that ageing users are still unable to make the most of them. Partially this is for cultural reasons, as their cohorts have not been exposed to technology-based products as much as the younger population. Technology also has a less important symbolic meaning for them and it is more a functional possession. As technology becomes more pervasive we should expect this lack of familiarity to reduce among the elderly. However such phenomenon may in part be also attributed to the inability of comparing technology-based products to any other category of products that could be used as archetype for learning. This may not change in the future as technology are changing so fast that developed archetypes may become obsolete and redundant quickly.

To take a poignant example form the study let us consider the smart phone. Smart phones were hardly regarded as phones by the participants; they rather thought of them as devices with hybrid functionalities, -a phone, a digital camera, an MP3 player, a GPS and a PC-. This confused the users as it gave them an unclear pathway to activate the relevant PBD. To exacerbate the confusion, the users had scarce familiarity with the SKBs that would have helped an expert (Moreau et al 2001) but not a novice in understanding how to use the technology. The vast majority of participants still preferred to use the landline phones to make voice calls and kept their mobiles for emergency situations. Those who own a smart phone limited considerably its use to just the functionalities that are archetypical of the mental model of 'mobile phone' they were familiar with: receive-make voice calls and messaging. The feasible transfer of knowledge from a traditional phone to a smart phone is therefore limited to those functionalities that are similar, while inferential analogy failed for the rest. As the conceptual distance between the devices (traditional mobile phone and smart phone) is too wide, the users are not in the position to envisage how a smart phone can be working as a GPS system or perform some tasks that a PC does, while also being a mobile phone. Furthermore, the integration in a smart phone of devices that don't have an isomorphic relation with a phone, hinders greatly the ability to imagine how functions mapped on to a previous form (e.g. finding directions with a GPS) could relate to a very differently shaped device. This demonstrates how the further a new product is from a dominant mental image of a product, the harder it is for the user to structure their understanding of the new product (Rampino 2011).

This leads us to argue that smart phones, as well as perhaps other technology-based products, can simultaneously represent a disruptive 
innovation for the ageing market while a continuous innovation for the younger audience. The findings, despite suggesting that the ageing participants consider smart phones disruptive innovations, do not seem to follow the Moreau et al's logic (2001) by which novices should find easier to learn disruptive innovation. The proposed answer to this dilemma is that the integration of many new products into one device represents a compound complexity, or innovation overload problem, that ageing users resolve by adopting the coping strategies we have discussed above: delegation, selective use, training and reliance on aids. A similar array of strategies has been put forward by Yoon et al (2009) in the generic context of consumer decision-making. In line with this research, which argued that the selection of a coping strategy depends on the fit between tasks-contextual environment and the characteristics of the consumer, our study claims that the social environment around the ageing user is important in the scaffolding of the coping strategies adopted by the user. In many observed instances the users made use of the social resources available to make sense of the new products, not just for delegating tasks, but also to gather an understanding of the benefits that the technology-based products could bring to his/her own life and consequently decide a coping strategy for innovation adoption (in toto or selectively).

Analogical mapping has also been considered responsible for creating a filter effect on the features of a new product a user retains (Gregan-Paxton et al 2002). By focusing on what is familiar (what is mapped) the user is cognitively discouraged to consider what is different in the new product and this can generates real difficulty when multifunction devises are brought to the market, a current trend in new technology. Despite all sorts of digital devices have been available for long time, their design, functionalities and interaction styles are still a challenge for ageing people. This, together with a naturally decrease in cognitive processing, such as memory and learning, set the older users apart. Having argued that technology-based products represent still a source of Innovation Overload, the findings of this research have discussed what role analogical learning plays and what other coping strategies are put in place when the former fails to work. In this emerging landscape where innovation is not univocally perceived and, consequently, products are diversely adopted, the role of design and marketing strategies are important to conceptualize new products and communicate their benefits. To reduce the digital divide, enhance participation and promote independent living, these traditionally unrelated domains ought to persuade consumers that technology are not out of the reach of their comprehension by using design that is adaptable and business strategies that are modular. By reflecting the diversity as well as the developmental achievements of novice users, technologybased products can become more flexible and appeal to diverse market segments simultaneously.

\section{Conclusions}

Hoeffler a decade ago firmly stated that besides having a winning product, a firm had to make the strategic decision of how to describe the product to make it successful on the market (2003). Due to the diversity in the consumers characteristics, firms now face the dilemma of what message to 
privilege; whether to appeal to the market by stressing the inherent novelty of a new product or the familiar features that may recall an archetypical device. The multiple sense-making, or flexible interpretation, that consumers make of innovative products challenges businesses at their core posing the problem of whether it is possible to design inclusively yet still innovatively, without disenfranchising early adopters and younger audiences.

By focusing on the learning strategies adopted by users, this paper makes a compelling case for a user-centred, opposite to a technology-centred, categorization of innovation. A global ageing society represents a place where the perception and adoption of innovation may vary according to the consumers' multiple and parallel socio-cultural contexts. The research presented here represents a reflection on a specific demographic group, the 60 plus, dealing with a particular category of products, technology; however this problem extends to a multitude of product categories that, thanks to embedded technology, become smarter and possibly more unapproachable by the day.

\section{References}

Baglieri, E. 2003. Dall'ldea al Valore. Milano Etas Libri

Baltes, P.B. and Plank M. 1993 The Aging Mind: Potential and Limits. The Gerontologist, 5(3): 580-594

Bakardjieva M and Smith R (2001) The Internet in everyday life: computer networking from thestandpoint of the domestic user. New Media \& Society 3(1): 67-83.

Burdek, B.E. 2005. Design: History, Theory and Practice of Product Design. Boston: Birkhauser

Christensen, C. 1997. The Innovator's Dilemma: When New Technologies Cause Great Firms to Fail. Harvard Business Review Press

Drolet, A., Shwartz, N. and Yoon, C. (eds) 2010. The Aging Consumer: Perspectives From Psychology and Economics. Routledge

Durand, T. 1992. Dual Technology trees: assessing the intensity and strategic significance of technology change. Research Policy. 21: 361-380

Eurostat (Statistical Office of the EU). 2010. Union Eurostat demographic. Available at: http://epp.eurostat.ec.europa.eu/portal/page/portal/population/documents/Tab/ report.pdf (accessed 2 February 2015)

Freeman, C. and Soete, L. 1987. Technical Change and Full Employment (eds), Basic Blackwell

Gentner, D. 1989. The Mechanisms of Analogical Transfer. In: Similarity and 
Analogical Reasoning, (eds). Vosniadou, S. and Ortony, A. Cambridge, UK: Cambidge University Press.

Gentner, D. 1983. Structure-mapping: A theoretical framework for analogy. Cognitive Science, 7: 155-170.

Gregan-Paxton, J., Hibbard, J.D.Frédéric F.Brunel, F.F. and Azar, P. 2002. So That's What That is: Examining the Impact of Analogy on Consumers' Knowledge Development for Really New Products. Psychology \& Marketing, 19 (June): 533-550.

Gregan-Paxton, J. and John, D. R.1997. Consumer learning by analogy: A model of inbnternal knowledge transfer. Journal of Consumer Research, 24: 266-284.

Griffith T. L. 1999. Technology Features as Triggers for Sensemaking. Academy of Management Review, 24(3): 472-488

Herbig, P. A. and Kramer, H.1992. The phenomenon of innovation overload. Technology in Society, 14(4): 441-461

Herbig, P. A. and Kramer, H. 1994. The Effect of Information Overload on the Innovation Choice Process: Innovation Overload. Journal of Consumer Marketing, 11(2): 45-54

Hoeffler, S. 2003.Measuring Preferences for Really New Products. Journal of Marketing Research. 40(4): 406-420

Klein, G. A. 1987. Analytical versus Recognitional approaches to design decision making. In Behavoural Perspectives in Designers, Tools and Organisations (eds). Rouse, W. and Boff, K. New York: North Holland 42-67

Lehmann, D. R.1997. A different game: Setting the stage. In Marketing science report: 97-118. Boston: Marketing science institute.

Lilien G., Morrison P.D., Searls K., Sonnack M., von Hippel E. 2002. Performance assessment of the lead user generation process for new product development. Management Science 48:1042-1059

Miles, M. and HubermanA. M.1994. Qualitative Data Analysis. Thousand Oaks, CA: Sage Publications.

Moore, G. C., and Benbasat, I. 1991. Development of an Instrument to Measure the Perceptions of Adopting an Information Technology Innovation. Information Systems Research 2(3):192-222.

Morrison P.D., Roberts J.H., Midgley D.F. 2004. The nature of lead users and measurement of leading edge status. Research Policy 33:351-362

Moreau, C.P., Lehmann, D.R. and Markman, A.B. 2001. Entrenched 
Knowledge Structures and Consumer Response to New Products. Journal of Marketing Research, 38(1): 14-30

Office for National Statistics. 2009. Age structure of United Kingdom. Available at: http://www.statistics.gov.uk/populationestimates/flash_pyramid/UK pyramid/pyramid6_30.html (accessed 2 February 2015).

Olson E.L. and Bakke G. 2001. Implementing the lead user method in a high technology firm: A longitudinal study of intentions versus actions. Journal of Product Innovation Management, 18:388-395

Pavitt, K. 1984. Sectoral Patterns of technical change: towards a taxonomy and theory. Research Policy, 13(6): 343-373

Population Reference Bureau. 2010. World population data sheet available at: http://www.prb.org/pdf10/10wpds_eng.pdf (accessed 2 February 2015).

Price, L.L., Arnould, E.J. and Curasiet C.F. 2000. Older consumers' disposition of special possessions. Journal of Consumer Research, 27(2): 179-201

Rampino, L. 2011. The Innovation Pyramid: A Categorization of the Innovation Phenomenon in the Product-design Field. International Journal of Design, 5(1): 3-16

Rogers, E. 1995. Diffusion of Innovations. Free Press, New York,

Rogers, E. M., and Shoemaker, F. F. 1971. Communication of Innovations: $A$ Cross-Cultural Approach. Free Press, New York.

Venkatesh, V., Morris, M.G., Davis, F.D., and Davis, G.B. 2003. User Acceptance of Information Technology: Toward a Unified View. MIS Quarterly, 27(3): 425-478

Verganti, R. 2002. Gestire l'innovazione design-driven. In Zurlo, F., Cagliano R., Simonelli, G. and Verganti R. (eds), Innovare con il Design. Milano: II Sole 24 Ore.

von Hippel, E. 2005. Democratizing innovation: The evolving phenomenon of user innovation. Journal für Betriebswirtschaft, 55 (1): 63-78

von Hippel, E. 1988. The sources of innovation. New York: Oxford University Press.

Weick, K. E. (1993). The collapse of sensemaking in organizations: The Mann Gulch disaster. Administrative Science Quarterly, 38, 628-652.

Weick, K. E. (1995). Sensemaking in organizations. Thousand Oaks, CA: Sage. 
Wixon, D., Holtzblatt, K. and Knox, S. 1990. Contextual Design: An Emergent View of System Design. In Proceedings of CHI '90: Conference of Human Factors in Computing Systems, 1990. Seattle, WA.

Womak, J. P., Jones D. T. and Ross, D. 1991. The machine that changed the world:the story of lean production. New York: Harper Business

Yoon, C., Cole, C. A. and Lee, M. 2009. Consumer Decision Making and Aging: Current Knowledge and Future Directions. invited target article for Research Dialogues, Journal of Consumer Psychology, 19 (1):12-16.

\section{Contributor Details}

Gabriella's research interests have attracted external funds from the Engineering and Physical Sciences Research Council, the National Police Improvements Agency, the technology Strategy Board and The DAIWA foundation. She has 15 years experience in designing interaction, technologies and communication, starting from the users. Her recent research interests locate Gabriella's expertise is at the interface between design and consumer studies where most of her work now resides.

Prior to her doctoral studies Gabriella worked at the research centre of Domus Academy (Italy), the Human Factors and Ergonomic Lab at Eastman Kodak (NY) and the Appliance studio (UK). Throughout her academic career Gabriella has applied user-centred approaches to product/service/system design and commercialisation. She is interested in inclusive design as a pathway to innovate design strategies and researched the effects of ageing on identity and on decision-making. She continues her work as consultant to make her research socially and commercially relevant. She has been a consultant for Age UK, The Royal National Institute for the Blind, Panasonic, Homebase, NDS systems. She has spent her graduate placement during her $\mathrm{PhD}$ at IDEO.

Gabriella is a visiting scholar at the Helen Hamlyn Centre, RCA, London and has also collaborated with the Innovation Lab at Todai.

Contact:

Email: gabriella.spinelli@brunel.ac.uk 